\title{
Testing Nested Additive, Multiplicative, and General Multitrait-Multimethod Models
}

\author{
Germà Coenders \\ School of Management and Business Administration \\ University Ramon Llull \\ Willem E. Saris \\ Department of Methods and Techniques \\ University of Amsterdam
}

\begin{abstract}
The article gives alternatives to Campbell and O'Connell's (1967) definitions of additive and multiplicative method effects in multitrait-multimethod (MTMM) data. The alternative definitions can be formulated by means of constraints in the parameters of the correlated uniqueness (CU) model (Marsh, 1989), which is first reviewed. The definitions have 2 major advantages. First, they allow the researcher to test for additive and multiplicative method effects in a straightforward manner by simply testing the appropriate constraints. An illustration of these tests is given. Second, the alternative definitions are closely linked to other currently used models. The article shows that CU models with additive constraints are equivalent to constrained versions of the confirmatory factor analysis model for MTMM data (Althauser, Heberlein, \& Scott, 1971; Werts \& Linn, 1970). In addition, Coenders and Saris (1998) showed that, for designs with 3 methods, a CU model with multiplicative constraints is equivalent to the direct product model (Browne, 1984).
\end{abstract}

Multitrait-multimethod (MTMM) designs (Campbell \& Fiske, 1959) consist of multiple measures of a set of factors (traits) with the same set of measurement procedures (methods). So these designs include $t \times m$ measures, that is, the number of methods $(m)$ times the number of traits $(t)$. The differences between methods can be

Requests for reprints should be sent to Germà Coenders, Faculty of Economics, University of Girona, Campus Montilivi, 17071 Girona, Spain. E-mail: coenders@econ.udg.es 
any design characteristic that can be shared by measurements of all traits, such as different response scale lengths or category labels in questionnaires, different data collection procedures, different raters, and so on.

Campbell and Fiske (1959) suggested using MTMM designs for convergent and discriminant validation by directly examining the elements of the correlation matrix among all $t \times m$ measurements, called MTMM matrix. This approach was cumbersome and often led to confusion (Schmitt \& Stults, 1986), so that from the early seventies MTMM matrices began instead to be analyzed by means of covariance structure analysis models (see for instance Bollen, 1989, as a general reference and Schmitt \& Stults for applications on MTMM data). These models are called MTMM models.

Many different MTMM models have been suggested in the literature. Among them are the correlated uniqueness (CU) model (Marsh, 1989; Marsh \& Bailey, 1991); the confirmatory factor analysis (CFA) model for MTMM data (Althauser et al., 1971; Alwin, 1974; Werts \& Linn, 1970); the direct product (DP) model (Browne, 1984, 1985); and the true score model for MTMM data (Saris \& Andrews, 1991).

The discussion about which of these models should be preferred has traditionally been linked to a discussion on the behavior of method effects, which determines to a large extent the structure of the MTMM matrix. Campbell and O'Connell (1967) described two such alternative structures linked to two types of method effects: additive and multiplicative. At that time, the direct examination of correlation coefficients was still common practice so that Campbell and O'Connell's conceptualization was not model based but referred to the correlations themselves.

It took some time before clear links could be established between the concepts of additive and multiplicative correlation structures and the models used by practitioners. In fact, the terminology used in 1967 by Campbell and O'Connell led to some misunderstanding. Some literature suggested that additive statistical models such as the CFA and CU models were suitable only for analyzing additive MTMM structures (for instance, Bagozzi, 1993; Bagozzi \& Yi, 1991; Cudeck, 1988; Schmitt \& Stults, 1986). The DP model was expressly developed for multiplicative structures and, partly as a result of this misunderstanding, quickly gained popularity.

Kumar and Dillon (1992) pointed out that, in principle, the additive versus multiplicative conceptualization in Campbell and O'Connell (1967) had nothing to do with the additive versus multiplicative formulation of the models. Although these authors, and also Dudgeon (1994), stated under which circumstances the CFA model produces additive or multiplicative structures, their conclusions were not at all straightforward. Browne (1989) also did a great deal of analytical work to relate the DP model to a competing additive components of covariance model suggested in Wothke (1984). Coenders and Saris (1998) showed that, under certain 
circumstances, the DP model was equivalent to a constrained CU model. The complicated relations among the models also make it difficult to test for additive and multiplicative method effects.

Meanwhile, Cudeck (1989) warned against the problems of scale dependence of the estimates of some structural equation models. In this respect, the author defined and distinguished scale dependent and scale invariant models. In short, it was shown that scale transformations can lead to different solutions and different fit statistics for scale-dependent models. Because standardization is one possible scale transformation, the problems mentioned by Cudeck can occur when comparing an analysis based on a covariance matrix to an analysis based on a correlation matrix (see Cudeck, 1989, for details). As a result, there is an increasing interest in specifying scale invariant MTMM models and in fitting MTMM models to covariance rather than correlation matrices. The latter makes the link between the models and the definitions in Campbell and O'Connell (1967) even more difficult.

This article gives alternative definitions of additive and multiplicative method effects that can easily be implemented by introducing constraints on the CU model parameters. The alternative definitions make it possible to test for additive and multiplicative method effects in a direct way by simply testing the constraints introduced on the $\mathrm{CU}$ model. An illustration of the tests is provided. Moreover, the alternative definitions can be directly related to the currently used models, and the relations among these models are reviewed. In particular, when appropriate additive constraints are introduced, the $\mathrm{CU}$ model is equivalent to restricted versions of the CFA model. Similarly, when appropriate multiplicative constraints are introduced, the CU model is equivalent to the DP model for designs with $m=3$.

\section{MTMM MATRICES AND MODELS}

\section{The Structure of an MTMM Matrix}

We next introduce some general comments on the elements of an MTMM matrix and discuss the typical structure of such a matrix. A survey of perceived life satisfaction carried out in Catalonia (Spain) in 1989 is used for illustration throughout the article. The study considered $t=3$ domains of life satisfaction (traits):

1. Life as a whole $(t 1)$.

2. Financial situation $(t 2)$.

3. Social contacts $(t 3)$.

Each trait was measured with $m=3$ response scales with ends labeled completely dissatisfied and completely satisfied. The methods were 
1. 100-point numeric scale $(m 1)$.

2. 5-point scale with all-labeled categories $(\mathrm{m} 2)$.

3. 11-point scale $(\mathrm{m} 3)$.

Details on the questionnaire and data collection can be found in Batista-Foguet, Coenders, and Sureda (1996). The sample size is 406. The correlation matrix and the standard deviations of the nine measurements are given in Table 1.

Campbell and Fiske (1959) suggested summarizing an MTMM data set by means of the MTMM matrix that arranges the correlation matrix among all measurements ordered by method. The authors referred to the different elements of such an MTMM correlation matrix as follows: monotrait-heteromethod correlations involve two measurements of the same trait using different methods; heterotrait-monomethod correlations involve two measurements of different traits using the same method; and heterotrait-heteromethod correlations involve two measurements of different traits using different methods. The labels of the variables in Table 1 and the presentation of the matrix in blocks following the method should help the reader locate the different types of correlations.

All measures contain random measurement errors. In addition to these errors, the methods used often produce a systematic response error, which is called method effect. So, in addition to trait or valid variance, MTMM measurements have two sources of error variance: noise or random error variance and method or invalid variance. Because the second source of error variance is common for all measurements using the same method, the resulting error terms are correlated.

Random measurement errors tend to attenuate the correlations among observed measurements with respect to the correlations among the trait factors. On the contrary, correlated measurement errors usually increase the correlations among observed measurements in absolute value (at least if trait correlations are positive). In an MTMM correlation matrix, heterotrait-monomethod correlations (which are in

TABLE 1

Correlations and Standard Deviations of Nine Measurements of Perceived Life Satisfaction

\begin{tabular}{lccc|ccc|ccc}
\hline Variable & $t 1 \mathrm{ml}$ & $t 2 \mathrm{ml}$ & $t 3 \mathrm{ml}$ & $t 1 \mathrm{~m} 2$ & $t 2 \mathrm{~m} 2$ & $t 3 \mathrm{~m} 2$ & $t 1 \mathrm{~m} 3$ & $t 2 \mathrm{~m} 3$ & $t 3 \mathrm{~m} 3$ \\
\hline $\mathrm{t} 1 \mathrm{~m} 1$ & 1.000 & & & & & & & & \\
$\mathrm{t} 2 \mathrm{~m} 1$ & 0.464 & 1.000 & & & & & & & \\
$\mathrm{t} 3 \mathrm{~m} 1$ & 0.340 & 0.223 & 1.000 & & & & & & \\
\hline $\mathrm{t} 1 \mathrm{~m} 2$ & 0.574 & 0.241 & 0.330 & 1.000 & & & & & \\
$\mathrm{t} 2 \mathrm{~m} 2$ & 0.349 & 0.762 & 0.195 & 0.300 & 1.000 & & & & \\
$\mathrm{t} 3 \mathrm{~m} 2$ & 0.175 & 0.019 & 0.646 & 0.390 & 0.119 & 1.000 & & & \\
$\mathrm{t} 1 \mathrm{~m} 3$ & 0.639 & 0.346 & 0.309 & 0.630 & 0.326 & 0.281 & 1.000 & & \\
$\mathrm{t} 2 \mathrm{~m} 3$ & 0.399 & 0.788 & 0.166 & 0.251 & 0.791 & 0.052 & 0.420 & 1.000 & \\
$\mathrm{t} 3 \mathrm{~m} 3$ & 0.276 & 0.121 & 0.657 & 0.282 & 0.143 & 0.692 & 0.445 & 0.237 & 1.000 \\
\hline$S D$ & 24.079 & 24.901 & 22.986 & 0.943 & 1.054 & 0.937 & 2.163 & 2.325 & 2.102 \\
\hline
\end{tabular}


the triangular blocks in Table 1) are in general larger in absolute value than heterotrait-heteromethod correlations (which are outside the diagonal of the square blocks in Table 1). In this respect, see, for instance, Andrews (1984).

Additive and multiplicative MTMM structures differ by the pattern of the aforementioned differences between heteromethod and monomethod correlations. Campbell and O'Connell (1967) suggested plotting monomethod correlations (vertical axis) against heteromethod correlations (horizontal axis) for all pairs of traits. The structure was called additive if, for any given two methods, there was a unit-slope linear relationship between the heterotrait-monomethod correlations involving one of the two methods and the heterotrait-heteromethod correlations. The structure was called multiplicative if the slope of such relationship was larger than one-in other words, if the differences between monomethod and heteromethod correlations were higher when the heteromethod correlations were higher.

MTMM models are useful to provide the researcher with measurement quality estimates (usually in the form of a variance decomposition into trait, error, and method variance) and corrected trait correlations, taking random and correlated measurement errors into account. We next review one such MTMM model, the $\mathrm{CU}$ model, which will be considered throughout the article. Other models will be reviewed in later sections and then related to the $\mathrm{CU}$ model.

\section{CU Model}

The CU model (Kenny, 1976; Marsh, 1989; Marsh \& Bailey, 1991) belongs to the family of factor analysis models. The model is specified as

$x_{i j}=\lambda_{i j} \xi_{i}+\delta_{i j} \quad \forall \mathrm{i}, \mathrm{j}$

where $x_{i j}$ is the measurement of trait $i$ with method $j$, expressed in deviations from the mean; $\delta_{i j}$ is the random measurement error plus method effect component for $x_{i j}$; $\xi_{i}$ are the standardized trait factors with correlations $\phi_{i i} ;$, and $\lambda_{i j}$ is the loading of $x_{i j}$ on $\xi_{i}$ (when standardized and squared it can be interpreted as a measurement quality indicator).

The specification includes the conventional assumption of no correlation between trait factors and error terms:

$\operatorname{cov}\left(\delta_{i j} \xi_{i^{\prime}}\right)=0 \quad \forall i j, i^{\prime}$

where $i, i^{\prime}, \ldots$ identify the traits, and $j, j^{\prime}, \ldots$ the methods. Note that, in all equations in this article, $i$ may be equal to $i^{\prime}$ and $j$ may be equal to $j^{\prime}$, unless the opposite is expressly stated. 
Covariances among error terms corresponding to pairs of variables measured with the same method (monomethod error covariances) constitute unrestricted model parameters that are represented as $\operatorname{cov}\left(\delta_{i j} \delta_{i^{\prime} j^{\prime}}\right)$. The inclusion of such parameters is a very straightforward manner of accounting for method effects. Covariances among error terms corresponding to pairs of variables measured with two different methods (heteromethod error covariances) are constrained to be zero:

$\operatorname{cov}\left(\delta_{i j} \delta_{i^{\prime} j^{\prime}}\right)=0 \quad$ if $j \neq j^{\prime}$

The model is then misspecified if the $\operatorname{cov}\left(\delta_{i j} \delta_{i^{\prime} j^{\prime}}\right)$ terms are not equal to zero. We return to this issue in the discussion.

The path diagram in Figure 1 displays the model for a design with $t=3$ traits and $m=3$ methods. The variables measured with the same method appear together in the diagram. Note that each variable is only affected by one trait factor and an error term. Note also the error covariances for the pairs of variables measured with the same method. The CU model is scale invariant and can be shown to lead to the following implied variances and covariances:

$$
\begin{array}{ll}
\operatorname{var}\left(x_{i j}\right)=\lambda^{2}{ }_{i j}+\operatorname{var}\left(\delta_{i j}\right) & \\
\operatorname{cov}\left(x_{i j} x_{i^{\prime} j^{\prime}}\right)=\lambda_{i j} \phi_{i i^{\prime}} \lambda_{i^{\prime} j^{\prime}} & \text { if } i \neq i^{\prime} \text { and } j \neq j^{\prime} \\
\operatorname{cov}\left(x_{i j} x_{i^{\prime} j}\right)=\lambda_{i j} \phi_{i i^{\prime}} \lambda_{i^{\prime} j}+\operatorname{cov}\left(\delta_{i j} \delta_{i^{\prime} j}\right) & \text { if } i \neq i^{\prime} \\
\operatorname{cov}\left(x_{i j} x_{i j^{\prime}}\right)=\lambda_{i j} \lambda_{i j^{\prime}} & \text { if } j \neq j^{\prime}
\end{array}
$$

where $\operatorname{var}\left(x_{i j}\right)$ is a variance, $\operatorname{cov}\left(x_{i j} x_{i^{\prime} j^{\prime}}\right)$ is a heterotrait-heteromethod covariance, $\operatorname{cov}\left(x_{i j} x_{i^{\prime} j}\right)$ is a heterotrait-monomethod covariance, and $\operatorname{cov}\left(x_{i j} x_{i j^{\prime}}\right)$ is a monotrait-heteromethod covariance. The terms $\operatorname{cov}\left(\delta_{i j} \delta_{i^{\prime} j}\right)$, which are added to the heterotrait-monomethod covariances, generally make them larger than the corresponding heterotrait-heteromethod covariances. The equation also decomposes the variance of the $x_{i j}$ variables into trait variance $\left(\lambda^{2}{ }_{i j}\right)$ and error variance $\left(\operatorname{var}\left(\delta_{i j}\right)\right)$, the latter including both random error and method variance.

A particularly interesting case of the $\mathrm{CU}$ model is the congeneric measurement (CM) model, one of the most commonly used measurement error models (Jöreskog, 1969, 1971). It is not an MTMM model, but its simplicity is such that it has sometimes been used for the analysis of MTMM data, especially if method effects are low (Widaman, 1985). The specification of the CM model is identical to that of the CU model except for Equation 3, which is reexpressed as

$$
\operatorname{cov}\left(\delta_{i j} \delta_{i^{\prime} j^{\prime}}\right)=0 \quad \text { if } i \neq i^{\prime} \text { or } j \neq j^{\prime}
$$




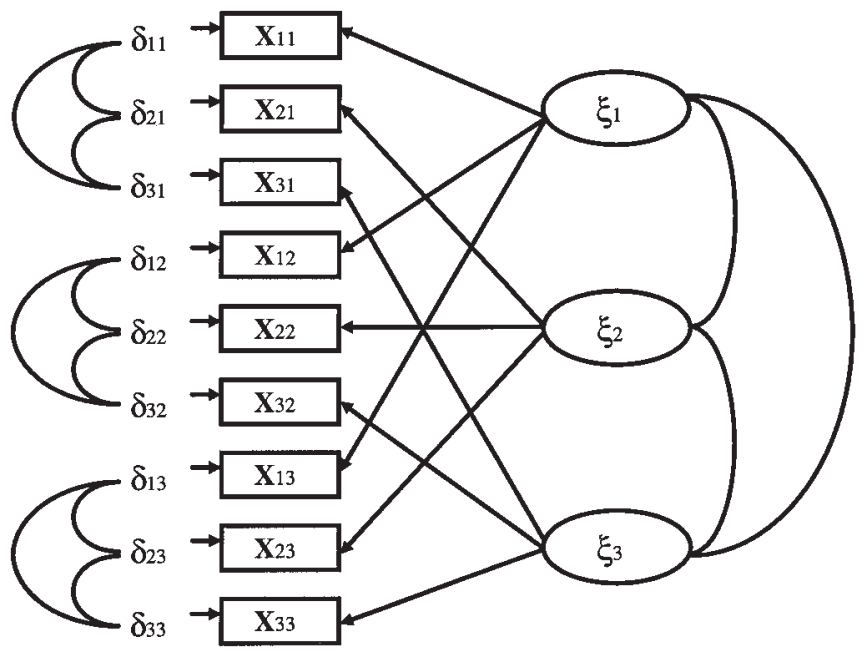

FIGURE 1 Path diagram of the CU model for three traits and three methods.

so that both heteromethod and monomethod error covariances are constrained to zero and method effects are thus ignored. If there are no method effects, the CM model is correct and scale invariant. If the method effects are important, the model is misspecified and the CU model should be used instead. Although the CU model has traditionally been linked to the modeling of additive method effects, it does not restrict monomethod error covariances at all, so that it may be used to model both additive and multiplicative method effects, as is shown in the next section.

\section{ALTERNATIVE DEFINITIONS OF ADDITIVE AND MULTIPLICATIVE METHOD EFFECTS}

This section gives two original alternative definitions of additive and multiplicative method effects that are more closely related to the current modeling approaches than the ones given in Campbell and O'Connell (1967) and in Browne (1984).

The definitions assume that the CU model holds. This, of course, implies that heteromethod error covariances are zero; we come back to this issue in the discussion. The CU model suggests that method effects can be found in the parameters reflecting error covariances among variables measured with the same method, that is, the $\operatorname{cov}\left(\delta_{i j} \delta_{i^{\prime} j}\right)$ terms in Equation 4. Therefore, the different behaviors of the method effects will correspond to different patterns in these parameters. Accordingly, all the definitions that are next presented imply different restrictions on them. 


\section{Definitions}

Definition A1. Method effects are called additive if the population MTMM covariance matrix can be fitted by a CU model in which the error covariance parameters fulfill the restriction

$$
\operatorname{cov}\left(\delta_{i j} \delta_{i^{\prime} j}\right)=a_{j} \quad \forall j, i \neq i^{\prime}
$$

where $a_{j} \geq 0$ is a constant related to method $j$.

In other words, method effects are additive if all error covariance parameters related to method $j$ are equal. The MTMM covariance matrix is then said to have an additive structure.

Definition M1. Method effects are called multiplicative if the population MTMM covariance matrix can be fitted by a CU model in which the error covariance parameters fulfill the restriction

$$
\operatorname{cov}\left(\delta_{i j} \delta_{i^{\prime} j}\right)=b_{j} \phi_{i i^{\prime}} \quad \forall j, i \neq i^{\prime}
$$

where $b_{j} \geq 0$ is a constant related to method $j$ and $\phi_{i i^{\prime}}$ is the correlation between trait $i$ and trait $i^{\prime}$.

In other words, method effects are multiplicative if the error covariance parameters related to method $j$ are proportional to the trait correlation $\phi_{i i^{\prime}}$. They will be larger in absolute value if the trait correlation is larger in absolute value; they will be positive if $\phi_{i i^{\prime}}>0$ and negative if $\phi_{i i^{\prime}}<0$. The MTMM covariance matrix is then said to have a multiplicative structure.

Definitions A1 and M1 are appealing in their simplicity, but they are not problem free. It can be shown that a CU model with the restrictions in Equations 6 or 7 is scale dependent. Moreover, Definitions A1 and M1 are not justifiable if measurements with the same method have different units of measurement, although this situation is quite rare in MTMM designs. Definitions A2 and M2 solve both problems, thus leading to scale invariant models. It will be clear that these definitions are the same as A1 and M1 except for scale corrections.

Definition A2. Method effects are called additive if the population MTMM covariance matrix can be fitted by a CU model in which the error covariance parameters fulfill the restriction

$$
\operatorname{cov}\left(\delta_{i j} \delta_{i^{\prime} j}\right)=c_{j} \lambda_{i j} \lambda_{i^{\prime} j} \quad \forall j, i \neq i^{\prime}
$$


where $c_{j} \geq 0$ is a constant related to method $j$ and the $\lambda$ 's are trait loadings.

Definition M2. Method effects are called multiplicative if the population MTMM covariance matrix can be fitted by a CU model in which the error covariance parameters fulfill the restriction

$\operatorname{cov}\left(\delta_{i j} \delta_{i^{\prime} j}\right)=d_{j} \phi_{i i^{\prime}} \lambda_{i j} \lambda_{i^{\prime} j} \quad \forall j, i \neq i^{\prime}$

where $d_{j} \geq 0$ is a constant related to method $j$.

The definitions given in this article are not always equivalent to those given by Campbell and O'Connell in 1967, but they are closely linked to them, as is next shown for Definitions A2 and M2.

\section{Relationship Between Definitions A2 and M2 and the Campbell \& O'Connell Definitions}

Campbell \& O'Connell (1967) used the structure of monomethod and heteromethod correlations to distinguish between additive and multiplicative method effects. Therefore, the easiest way to link Definitions A2 and M2 with Campbell and O'Connell's is by deriving the monomethod and heteromethod correlations implied by the constrained CU models. This can be done directly because the CU model with the constraints in Definitions A2 and M2 is scale invariant and can therefore be equivalently fitted to covariance and correlation matrices.

The heteromethod correlation between measurements of traits $i$ and $i^{\prime}$, with methods $j$ and $j^{\prime}$ implied by the CU model is

$\rho\left(x_{i j} x_{i^{\prime \prime}}\right)=\lambda_{i j}^{*} \phi_{i i^{\prime}} \lambda_{i^{\prime j^{\prime}}}^{*^{\prime}} \quad$ if $i \neq i^{\prime}$ and $j \neq j^{\prime}$

where $\phi_{i i^{\prime}}$ stands for a trait correlation and $\lambda_{i j}^{*}$ for a standardized trait loading $\left(\left[\lambda_{i j}^{*}\right]^{2}\right.$ is the percentage of trait variance in $x_{i j}$, which can be interpreted as measurement quality).

If method effects are additive according to Definition A2, the corresponding monomethod correlation, with only method $j$, is

$\rho\left(x_{i j} x_{i^{\prime} j}\right)=\lambda^{*}{ }_{i j} \phi_{i i^{\prime}} \lambda_{i^{\prime} j}^{*^{\prime}}+c_{j} \lambda^{*}{ }_{i j} \lambda_{i^{\prime} j}^{*} \quad$ if $i \neq i^{\prime}$

and if method effects are multiplicative according to Definition M2,

$\rho\left(x_{i j} x_{i^{\prime} j}\right)=\lambda^{*}{ }_{i j} \phi_{i i^{\prime}} \lambda_{i^{\prime} j}^{*}+d_{j} \lambda^{*}{ }_{i j} \phi_{i i^{\prime}} \lambda_{i^{\prime} j}^{*} \quad$ if $i \neq i^{\prime}$ 
In both Equations 11 and 12 it can be seen that the monomethod correlation can be formulated as the addition of a trait component and a method component. The difference between the multiplicative and the additive cases lies in the behavior of the method component, which can be proportional to the trait correlation or independent of it.

Equations 10 and 11 imply the additive correlation structure in Campbell and O'Connell (1967) if all $\lambda^{* \prime}$ s are equal. In this case, Equations 10 and 11 result in the expression $\rho\left(x_{i j} x_{i^{\prime} j}\right)=\rho\left(x_{i j} x_{i^{\prime} j^{\prime}}\right)+c_{j}\left(\lambda^{*}\right)^{2}$, so that there is a unit-slope relationship between monomethod and heteromethod correlations as required by Campbell and O'Connell. In a similar way, when the $\lambda^{* \prime}$ s are equal, Equations 10 and 12 imply Campbell and O'Connell's multiplicative structure. In this case, $\rho\left(x_{i j} x_{i^{\prime}}\right)=(1+$ $\left.d_{j}\right) \rho\left(x_{i j} x_{i^{\prime} j^{\prime}}\right)$ so that the slope $1+d_{j}$ is larger than 1 , as required.

It has sometimes been argued that, when reliability differs across variables, the conceptualization due to Campbell and O'Connell (1967) is difficult to interpret. In fact, from the beginning, we were not satisfied about measurement quality playing a role in the type of MTMM structure. In this respect, Definitions A2 and M2 are more general as they continue to be meaningful no matter what the reliabilities are.

Our definitions of additive and multiplicative method effects are then closely related to the ones given by Campbell and O'Connell in 1967. Where Campbell and O'Connell refer to relationships among the correlations, we refer to a relationship or lack of relationship between error covariances and trait correlations. Additive method effects can then be viewed as an equal impact of measurement error covariances regardless of the trait correlation. Multiplicative method effects can be viewed as proportionality between error covariances and trait correlations.

Note that, although the statistical formulation of the equations in the $\mathrm{CU}$ model is certainly additive, the MTMM correlation structure implied by this model can be called additive in the sense of Campbell and O'Connell (1967) only when certain constraints are applied to the error covariances. Conversely, the CU model, being an additive model, can account for multiplicative MTMM correlation structures in the sense of Campbell and O'Connell only when error covariances follow a certain pattern. This is in agreement with the claim made by Kumar and Dillon (1992) that in principle the additivity of the model has nothing to do with the additivity of the structure of the MTMM matrix.

The fact that the definitions are implemented as constraints in the CU model allows for statistical testing. The next section provides guidelines on how to perform tests of additive and multiplicative method effects. An illustration is also given.

The CU model and its constrained cases are not only related to Campbell and O'Connell's definitions but also to other frequently used models for the analysis of MTMM data. One section is also devoted to this issue. 


\section{TESTING FOR ADDITIVE AND MULTIPLICATIVE METHOD EFFECTS}

\section{Fitting Constrained Additive and Multiplicative CU Models}

As stated in the previous section, additive or multiplicative method effects can be modeled by fitting a CU model with some appropriate constraints. In fact, method effects that conform to any of the four definitions given in this article can be modeled in the following way: $m \operatorname{cov}\left(\delta_{1 j} \delta_{2 j}\right)$ error covariances concerning Traits 1 and 2 are taken as free parameters and the remaining $\operatorname{cov}\left(\delta_{i j} \delta_{i^{\prime} j}\right)$ error covariances with $i \geq$ 1 and $i^{\prime}>2$ are expressed as a function of $\operatorname{cov}\left(\delta_{1 j} \delta_{2 j}\right)$. The unconstrained CU model has $m t(t-1) / 2$ free error covariances so that $m t(t-1) / 2-m$ constraints are involved. From now on we refer to a $\mathrm{CU}$ model specified with method effects conforming to Definitions A1, M1, A2, and M2 as a CUA1, CUM1, CUA2, or CUM2 model, respectively. The necessary constraints are given in the following for all four models:

CUA1: $\operatorname{cov}\left(\delta_{i j} \delta_{i^{\prime} j}\right)=\operatorname{cov}\left(\delta_{1 j} \delta_{2 j}\right) \quad \forall j, i \geq 1, i^{\prime}>2$

CUM1: $\operatorname{cov}\left(\delta_{i j} \delta_{i i^{\prime}}\right)=\operatorname{cov}\left(\delta_{1 j} \delta_{2 j}\right) \frac{\phi_{i i^{\prime}}}{\phi_{12}} \quad \forall j, i \geq 1, i^{\prime}>2$

CUA2: $\operatorname{cov}\left(\delta_{i j} \delta_{i^{\prime} j}\right)=\operatorname{cov}\left(\delta_{1 j} \delta_{2 j}\right) \frac{\lambda_{i j} \lambda_{i^{\prime} j}}{\lambda_{1 j} \lambda_{2 j}} \quad \forall j, i \geq 1, i^{\prime}>2$

$\operatorname{CUM} 2: \operatorname{cov}\left(\delta_{i j} \delta_{i^{\prime} j}\right)=\operatorname{cov}\left(\delta_{1 j} \delta_{2 j}\right) \frac{\phi_{i i^{\prime}} \lambda_{i j} \lambda_{i^{\prime} j}}{\phi_{12} \lambda_{1 j} \lambda_{2 j}} \quad \forall j, i \geq 1, i^{\prime}>2$

Note that all constraints referred to in this section make sense only if $t>2$. If $t=$ 2 , the unconstrained CU model has only $m$ error covariance parameters. Note also that if all trait correlations are equal, then the additive and multiplicative constraints become the same.

Nowadays, some standard programs for structural equation models include nonlinear constraints, thus making the estimation of these models possible. The appendix shows an input file for the LISREL8 program (Jöreskog \& Sörbom, 1989,1993 ) that can be used to estimate the CUM2 model for $t=3$ and $m=3$.

\section{Testing Additive and Multiplicative CU Models}

The test of additive and multiplicative method effects against a more general pattern for method effects can be formulated as a test of the constraints given in the previous section and can be made by comparing the fit of appropriate nested models. 
If the models are estimated by normal-theory maximum likelihood with a structural equation modeling program such as LISREL8, a great many test statistics and fit indexes can be computed (Tanaka, 1993). We agree with Browne and Cudeck (1993) that we should expect that most models are incorrectly specified and that therefore the usual test statistics are only of limited use. In addition, both test statistics and the now-popular fit indexes may be sensitive to different characteristics of the model. The sensitivity of test statistics to those characteristics can be taken into account, although it is rather complex to do so, as has been shown by Saris and Satorra (1988, 1993); Saris, Satorra, and Sörbom (1987); Saris and Stronkhorst (1984); and Satorra and Saris (1985). Without going into details, we suggest using the following procedure:

1. Check if the CU model is acceptable. This means that all theoretically possible parameters that are fixed to zero in the CU model must either have a substantively small value if estimated (i.e., must have a small expected parameter change [EPC]) or must be nonsignificant (i.e., must have a modification index smaller than 3.84 , which is the critical value at the .05 significance level assuming a chi-square distribution with $1 d f$ for the modification index). If the model is not acceptable, there is no reason to test any restrictions on it. If, however, the model is acceptable, the meaningful restrictions can be tested in the following steps.

2. Test the existence of method effects by comparing the nested CM and CU models using the chi-square change statistic. This statistic is computed as the difference in the chi-square test statistics of both models to be compared. If the most restrictive of both nested models holds and certain conditions are fulfilled (in this section it must be assumed that the $\delta_{i j}$ terms are normally distributed and the trait factors are either normal or independent from the $\delta_{i j}$ terms; see Satorra, 1990), then the chi-square change statistic should follow a chi-square distribution with the degrees of freedom equal to the difference in degrees of freedom between the two models. If the CM model is not rejected, it does not make sense to carry out any further tests as the existence of method effects is not supported.

3. Choose which additive and multiplicative definitions (A1 and M1 or A2 and M2) to test.

4. Perform the tests for additive and multiplicative method effects using the appropriate chi-square change statistics. Either test the CUA1 and CUM1 models against the CU model or test the CUA2 and CUM2 models against the CU model.

5. Interpret the results. There are four possible combinations of results of the tests of the additive and multiplicative hypotheses. Two of these combinations (reject the additive hypothesis but not the multiplicative one and reject the multiplicative hypothesis but not the additive one) allow the researcher to draw quite clear conclusions on the type of method effect structure that is present in the data. If neither the additive nor the multiplicative hypotheses are rejected, then no conclusions at all can be drawn. This can be the case if all trait correlations are nearly equal or if 
the sample is too small. If both hypotheses are rejected, then a structure that is more complicated than a simple additive or multiplicative one is revealed.

The tests were carried out on the data given in Table 1 as an illustration. The CM, CUA1, CUA2, CUM1, CUM2, and CU models were independently fitted on both the covariance and the correlation matrices by normal-theory Maximum Likelihood with the LISREL8 program. The degrees of freedom, chi-square test statistics, and associated $p$ values of all models for both types of matrix are shown in Table 2. As expected, scale invariant models yielded identical goodness-of-fit measures regardless of whether the correlation or the covariance matrix was analyzed. The five recommended steps are commented on in the following.

1. The CU model could be rejected at the .05 level because the test statistic is equal to 35.43 , which has a probability of only .002 if the CU model is exactly correct. On the other hand, the values to be expected for theoretically possible parameters that were constrained to zero (heteromethod error covariances) were rather small (the largest standardized EPC in absolute value was .11) and mostly nonsignificant. The standardized estimates obtained if the parameter with the largest EPC was included in the model were hardly different from those obtained with this parameter constrained to zero; most of the differences were around or below .02 . Therefore, we think that for all practical purposes the CU model can be seen as acceptable for this data set, and we display the actual estimates in Table 3. We consequently attribute the statistical rejection of the model to the probable high power of the chi-square test, caused by the fact that the standardized trait loadings are quite high (between .76 and .90) and that the sample size is relatively large (Saris \& Satorra, 1988; Saris et al., 1987).

TABLE 2

Goodness-of-Fit Summary of the Alternative Restricted Correlated Uniqueness (CU) Models

\begin{tabular}{|c|c|c|c|c|c|c|}
\hline & $C M$ & $C U A 1$ & $C U A 2$ & CUM1 & CUM2 & $C U$ \\
\hline $\begin{array}{l}\text { Degrees of freedom } \\
\text { Goodness of fit for the } \\
\text { analysis of the } \\
\text { covariance matrix }\end{array}$ & 24 & 21 & 21 & 21 & 21 & 15 \\
\hline $\begin{array}{l}\chi^{2} \text { statistic } \\
p \text { value } \\
\text { Goodness of fit for the } \\
\text { analysis of the } \\
\text { correlation matrix }\end{array}$ & $\begin{array}{r}239.18 \\
<.001\end{array}$ & $\begin{array}{l}53.04 \\
<.001\end{array}$ & $\begin{array}{c}60.98 \\
<.001\end{array}$ & $\begin{array}{l}62.48 \\
<.001\end{array}$ & $\begin{array}{l}62.90 \\
<.001\end{array}$ & $\begin{array}{l}35.43 \\
.002\end{array}$ \\
\hline $\begin{array}{l}\chi^{2} \text { statistic } \\
p \text { value }\end{array}$ & $\begin{array}{l}\text { Same as } \\
\text { above } \\
\text { Same as } \\
\text { above }\end{array}$ & $<.001$ & $\begin{array}{l}\text { Same as } \\
\text { above } \\
\text { Same as } \\
\text { above }\end{array}$ & $<.001$ & $\begin{array}{l}\text { Same as } \\
\text { above } \\
\text { Same as } \\
\text { above }\end{array}$ & $\begin{array}{l}\text { Same as } \\
\text { above } \\
\text { Same as } \\
\text { above }\end{array}$ \\
\hline
\end{tabular}




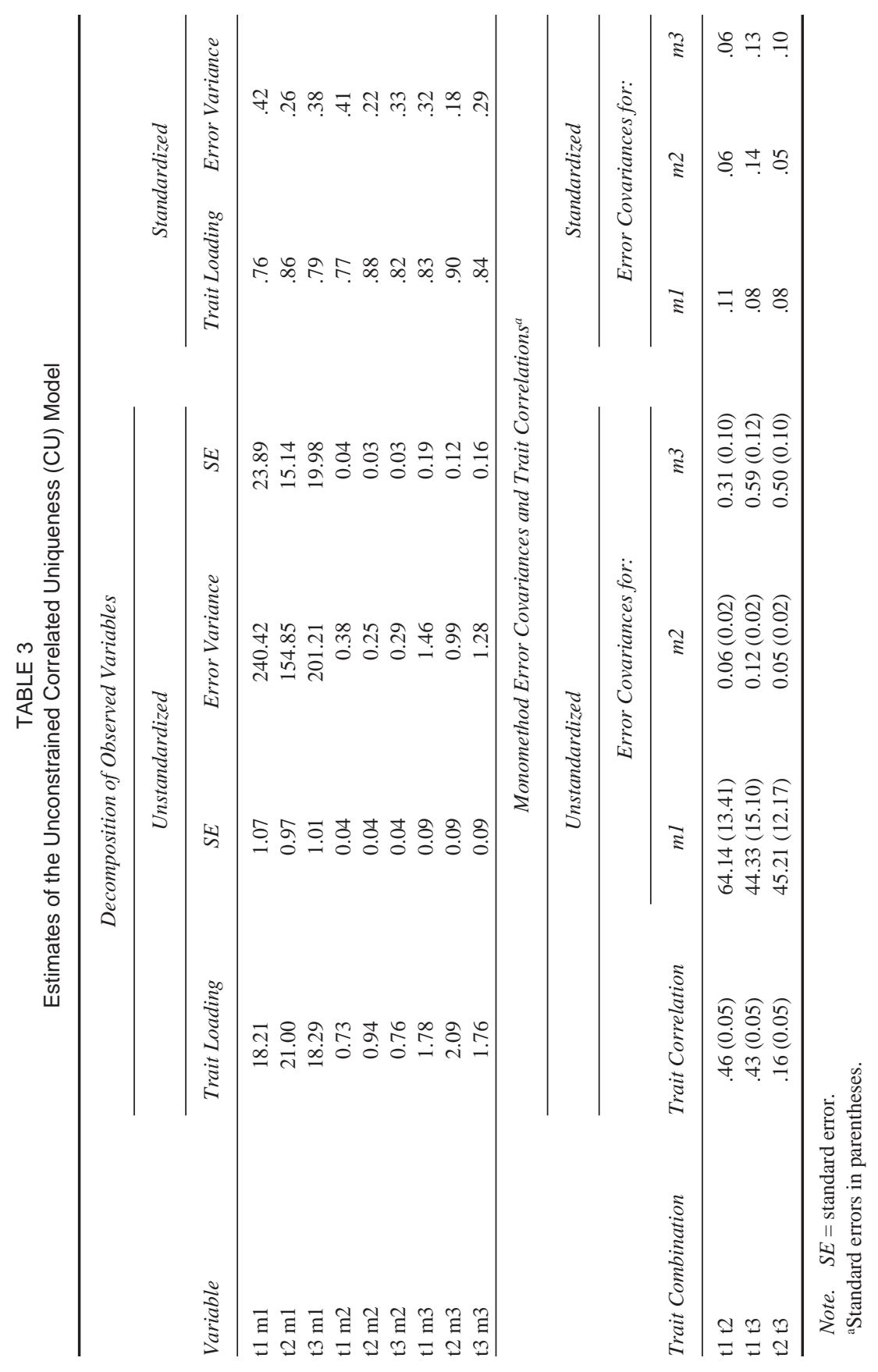


2. Table 2 allows us to reject the hypothesis of absence of method effects. The chi-square change statistic comparing the $\mathrm{CU}$ and $\mathrm{CM}$ models, which has $9 \mathrm{df}$ for this $t=3, m=3$ design, equals 203.75, and is significant compared to the usual standards. This result allows us to proceed with the tests of additive and multiplicative method effects. We consider the standardized estimates of the monomethod error covariances in Table 3 to be large enough so as not to attribute rejection to power alone.

3. Table 2 shows that the goodness of fit of the additive and multiplicative $\mathrm{CU}$ models can change depending on whether Definitions A1 and M1 or Definitions A2 and M2 are considered. Table 2 also shows that, if Definitions A1 and M1 are considered, the kind of matrix that is analyzed also has an influence because of the scale dependence of the models. This is one of the reasons why we suggest using Definitions A2 and M2, on which the remaining tests in this section are based.

4. Table 2 allows us to perform the test of the null hypothesis of additive method effects by comparing the CU and CUA2 models. The test is significant at the .0001 level (chi-square change $=25.55$, with $6 d f$ for this design). The test of the null hypothesis of multiplicative method effects can be computed in a similar fashion and is also significant at the .0001 level (chi-square change $=27.47$, also with $6 d f)$.

5. The tests show that, for this data set, both the additive and multiplicative method effects are rejected in favor of the more general pattern that is permitted by the $\mathrm{CU}$ model. Table 3 provides additional evidence for this more complicated pattern: If we consider the standardized estimates of the monomethod error covariances, we find large differences in the within-method error covariances, which constitutes a deviation from the additive pattern. However, these differences do not follow the size of trait correlations as demanded by the multiplicative pattern. For instance, Traits 1 and 2 have the highest correlation but a quite low error covariance for Methods 2 and 3. Traits 2 and 3 have the lowest correlation but a quite high error covariance with Method 3. The unrestricted CU model should then be preferred.

\section{RELATIONSHIP OF THE CONSTRAINED CU MODELS TO OTHER MODELS FOR MTMM DATA}

In this section we show that the constrained CU models presented in this article are not only related to the definitions given by Campbell and O'Connell in 1967, but also to other models that are often used on MTMM data. These relationships also allow us to better interpret the assumptions and behavior of the models. A section is devoted to each of the CFA and DP models, including some constrained versions of them. All models are summarized together in Table 4 . After presenting each of the models, the equivalence relationships among them are referred to. These equiva- 
TABLE 4

Summary of the Models Presented in the Article

\begin{tabular}{|c|c|c|c|c|}
\hline Model & Method Factors & Error Covariances & $\begin{array}{c}\text { Type of Method } \\
\text { Effect }\end{array}$ & Scale \\
\hline $\mathrm{CU}$ & No & $\begin{array}{l}\text { Monomethod pairs of variables } \\
\text { Unconstrained }\end{array}$ & General & Invariant \\
\hline $\mathrm{CM}$ & No & No & None & Invariant \\
\hline CUA1 & No & $\begin{array}{l}\text { Monomethod pairs of variables } \\
\text { Constrained (definition A1) }\end{array}$ & $\begin{array}{l}\text { Additive (definition } \\
\text { A1) }\end{array}$ & Dependent \\
\hline CUM1 & No & $\begin{array}{l}\text { Monomethod pairs of variables } \\
\text { Constrained (definition M1) }\end{array}$ & $\begin{array}{l}\text { Multiplicative } \\
\quad \text { (definition M1) }\end{array}$ & Dependent \\
\hline CUA2 & No & $\begin{array}{l}\text { Monomethod pairs of variables } \\
\text { Constrained (definition A2) }\end{array}$ & $\begin{array}{l}\text { Additive (definition } \\
\text { A2) }\end{array}$ & Invariant \\
\hline CUM2 & No & $\begin{array}{l}\text { Monomethod pairs of variables } \\
\text { Constrained (definition M2) }\end{array}$ & $\begin{array}{l}\text { Multiplicative } \\
\quad \text { (definition M2) }\end{array}$ & Invariant \\
\hline CFA1 & $\begin{array}{l}\text { Uncorrelated with } \\
\text { trait factors }\end{array}$ & No & $\begin{array}{c}\text { General if } t=3 \text {. It } \\
\text { accounts for } \\
\text { heteromethod } \\
\text { error covars. }\end{array}$ & Invariant \\
\hline CFA2 & Uncorrelated & No & General if $t=3$ & Invariant \\
\hline CFA3 & $\begin{array}{l}\text { Uncorrelated } \\
\text { Constrained } \\
\text { loadings }\end{array}$ & No & $\begin{array}{l}\text { Additive (definition } \\
\text { A1) }\end{array}$ & Dependent \\
\hline CFA4 & $\begin{array}{l}\text { Uncorrelated. } \\
\text { Constrained } \\
\text { invalidities }\end{array}$ & No & $\begin{array}{l}\text { Additive (definition } \\
\text { A2) }\end{array}$ & Invariant \\
\hline DP & $\begin{array}{l}\text { Not a factor } \\
\quad \text { analysis model }\end{array}$ & Not a factor analysis model & $\begin{array}{l}\text { Multiplicative } \\
\quad \text { (definition M2) } \\
\text { if } m=3\end{array}$ & Invariant \\
\hline
\end{tabular}

Note. $\quad \mathrm{CU}=$ correlated uniqueness.

lence relationships are summarized in Figure 2. Throughout the article we understand equivalence as meaning local equivalence, as in Luijben (1989). Two equivalent models have the same number of free parameters and, for any set of parameters of one model, there exists a set of parameters of the other model that yields an identical implied covariance matrix. For two models to be locally equivalent, equivalence only needs to hold in the regions of the parameter spaces where the parameter values of both models are admissible and both models are identified. See Luijben (1989) for a more formal definition and examples.

\section{Classic CFA Model for MTMM Data}

The classic CFA model also belongs to the family of factor analysis models and is probably the model most frequently used to analyze MTMM data (Althauser et al., 


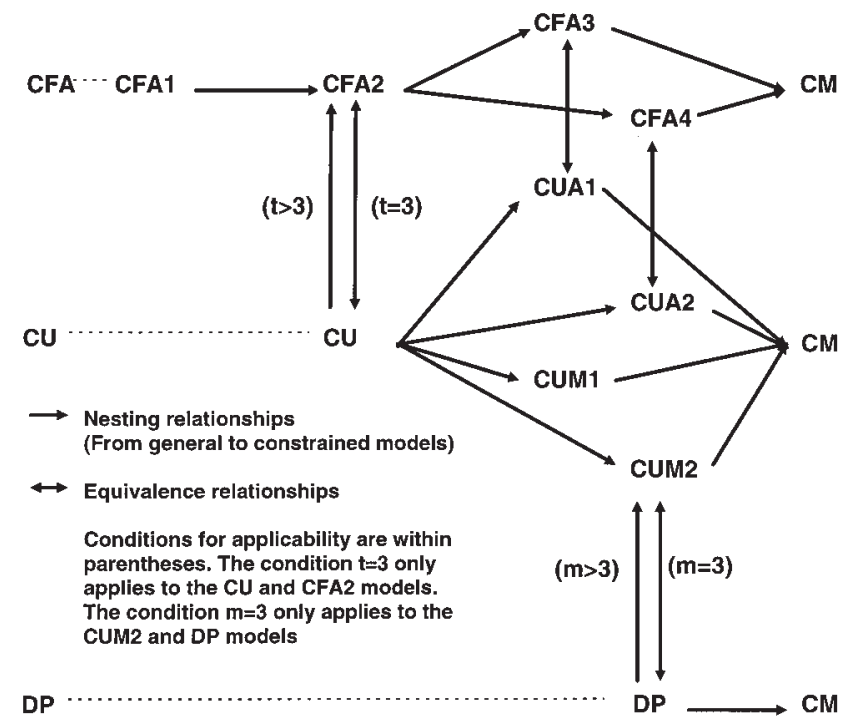

FIGURE 2 Nesting and equivalence relationships between the models defined in Table 4.

1971; Alwin, 1974; Werts \& Linn, 1970). In this model, error covariances are not specified, but each observed variable is allowed to load on both one trait factor and one method factor. The latter type of factors account for method effects. The model is specified as follows:

$x_{i j}=\lambda_{i j} \xi_{i}+\lambda_{M i j} \xi_{M j}+\delta_{i j} \quad \forall i, j$

where $x_{i j}$ is the measurement of trait $i$ with method $j$, expressed in deviations from the mean; $\delta_{i j}$ is the random measurement error for $x_{i j}$; $\xi_{i}$ are the standardized trait factors with correlations $\phi_{i i} ; \xi_{M j}$ are the standardized method factors; $\lambda_{i j}$ is the loading of $x_{i j}$ on $\xi_{i}$ (when standardized and squared it can be interpreted as a measurement quality indicator); and $\lambda_{M i j}$ is the loading of $x_{i j}$ on $\xi_{M j}$ (method effect indicator).

The model is usually specified with the standard assumptions of factor analysis models, including uncorrelated error terms, plus the additional assumption of uncorrelated method and trait factors:
$\operatorname{cov}\left(\delta_{i j} \xi_{i^{\prime}}\right)=0$
$\forall i j, i^{\prime}$
$\operatorname{cov}\left(\delta_{i j} \xi_{M j^{\prime}}\right)=0$
$\forall i j, j^{\prime}$
$\operatorname{cov}\left(\delta_{i j} \delta_{i^{\prime} j^{\prime}}\right)=0$
if $i \neq i^{\prime}$ or $j \neq j^{\prime}$ 
$\operatorname{cov}\left(\xi_{i} \xi_{M j}\right)=0$

$$
\forall i, j
$$

The assumption of no correlation between trait and method factors in Equation 19 makes it possible to decompose the variance of $x_{i j}$ into trait variance $\left(\lambda^{2} i j\right)$, method variance $\left(\lambda^{2} M_{i j}\right)$ and random error variance $\left(\operatorname{var}\left[\delta_{i j}\right]\right)$ to assess measurement quality (e.g., Schmitt \& Stults, 1986), although this assumption may not be reasonable under certain conditions (Kumar \& Dillon, 1992). From now on, we refer to a CFA model specified with the assumptions in Equations 18 and 19 as a CFA1 model.

Two additional sets of constraints are often introduced so as to avoid the frequent overparametrization problems of the CFA1 model, such as failure to converge, inadmissible estimates, or empirical underidentification (Andrews, 1984; Bagozzi \& Yi, 1991; Brannick \& Spector, 1990; Kenny \& Kashy, 1992; Marsh \& Bailey, 1991; Rindskopf, 1984; Saris, 1990b):

$$
\begin{array}{ll}
\operatorname{cov}\left(\xi_{M j} \xi_{M j^{\prime}}\right)=0 & \text { if } j \neq j^{\prime} \\
\lambda_{M i j}=\lambda_{M i^{\prime} j}=\lambda_{M j} & \forall i \neq i^{\prime}, j
\end{array}
$$

We will refer to a CFA model specified with the assumptions in Equations 18 to 20 as a CFA2 model. The path diagram in Figure 3 shows this model for a design with $t=3$ and $m=3$. This path diagram is identical to that of Figure 1 except for the specification of a set of uncorrelated method factors instead of the error covariances of the CU model. The CFA2 model is one of the particular cases of CFA1 described in Widaman (1985). The restriction of uncorrelated method factors (Equation 20) implies that only error covariances among indicators sharing the same method can be explained by the CFA2 model. In this respect, the CFA2 model behaves similarly to the CU model. In fact, Marsh (1989) showed that the CFA2 and CU models are equivalent for designs with $t=3$. If $t>3$, then the CFA2 model is nested into the CU model, and the $\mathrm{CU}$ model is thus more general. Unlike the CFA2 and CU models, the CFA1 model allows for heteromethod error covariances but leads to many kinds of problems, as mentioned previously. Both the CFA1 and CFA2 models are scale invariant.

The variances and covariances implied by the CFA2 model are

$$
\begin{aligned}
& \operatorname{var}\left(x_{i j}\right)=\lambda_{i j}+\lambda^{2}{ }_{M i j}+\operatorname{var}\left(\delta_{i j}\right) \\
& \operatorname{cov}\left(x_{i j} x_{i^{\prime} j}\right)=\lambda_{i j} \phi_{i i^{\prime}} \lambda_{i^{\prime \prime} j^{\prime}} \quad \text { if } i \neq i^{\prime} \text { and } j \neq j^{\prime} \\
& \operatorname{cov}\left(x_{i j} x_{i^{\prime} j}\right)=\lambda_{i j} \phi_{i i^{\prime}} \lambda_{i^{\prime} j}+\lambda_{M i j} \lambda_{M i^{\prime} j} \quad \text { if } i \neq i^{\prime}
\end{aligned}
$$


$\operatorname{cov}\left(x_{i j} x_{i j^{\prime}}\right)=\lambda_{i j} \lambda_{i j^{\prime}} \quad$ if $j \neq j^{\prime}$

In comparison to Equation 4, Equation 22 shows that the CFA2 model computes error covariances from the method loadings.

We refer to a CFA model specified with the assumptions in Equations 18 to 21 as a CFA3 model. The restriction of equality of method loadings within a method (Equation 21) implies constant error covariances within a method and can thus be linked to additive method effects according to Definition A1. Note that we drop one subindex from the method loading in Equation 21. Unlike the CFA1 and CFA2 models, the CFA3 model is scale dependent. The CFA3 model is used for instance in Andrews (1984) and Saris (1990b).

It is easy to see that the CUA1 and CFA3 models are equivalent. Both models have the same number of free parameters. Equations 4 and 22 become the same if we express the parameters of the CUA1 model as a function of the parameters of the CFA3 model in such a way that

1. The $\lambda_{i j}$ trait loadings and the $\phi_{i i}$ trait correlations take the same value in both models.

2. The error variances in the CUA1 model equal the error variances in the CFA3 model plus the $\lambda^{2}{ }_{M j}$ squared method loading.

3. The $a_{j}$ error covariances in the CUA1 model equal the $\lambda^{2}{ }_{M j}$ squared method loadings of the CFA3 model.

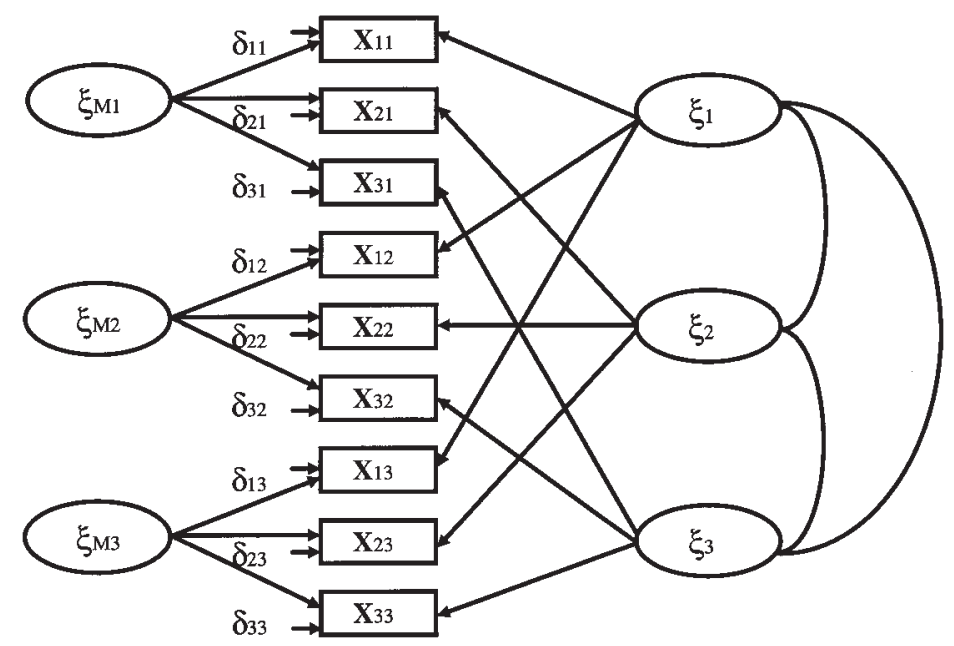

FIGURE 3 Path diagram of the CFA2 model for three traits and three methods. 
As required, for any set of CFA3 parameters there exists a set of CUA1 parameters that makes the implied variances and covariances of both models the same. The CFA3 and CUA1 models are then equivalent, which also means that they are both nested into the $\mathrm{CU}$ model. A test of the CFA3 model against the CU model can be interpreted as a test of additive method effects (according to Definition A1) against a more general pattern and, if desired, can be used as an alternative to the test presented in previous sections. The equivalence between the CUA1 and CFA3 models holds for any value of $m$ and $t$, provided that both models are identified.

It is also possible to formulate a scale invariant model of the CFA form that is equivalent to the CUA2 model. This can be done by following the approach of Coenders, Batista-Foguet, and Satorra (1995) and implies introducing the following constraint instead of that in Equation 21:

$\lambda_{M i j}=\lambda_{i j} \sqrt{ } c_{j} \quad \forall i, j$

where $c_{j} \geq 0$ is a constant related to method $j$.

Equation 23 constrains method loadings to be proportional to the trait loadings within a method, thus making the ratio of method variance over trait variance to be constant within a method. This is equivalent to making true score validity equal within a method (Coenders et al., 1995). We call a CFA model specified with the constraints in Equations 18, 19, 20, and 23 a CFA4 model.

It is a straightforward matter to show that the CUA2 and CFA4 models are equivalent. Both models have the same number of free parameters. Equations 4 and 22 become the same if we express the parameters of the CUA2 model as a function of the parameters of the CFA4 model in such a way that

1. The $\lambda_{i j}$ trait loadings, the $\phi_{i i}$ trait correlations, and the $c_{j}$ constant take the same value in both models.

2. The $\operatorname{var}\left(\delta_{i j}\right)$ error variances in the CUA2 model equal the error variances in the CFA4 model plus the $\lambda^{2}{ }_{i j} c_{j}$ squared method loading.

The CFA4 and CUA2 models are then equivalent for any value of $m$ and $t$, provided that both models are identified. This also means that they are both nested into the CU model. A test of the CFA4 model against the CU model can be interpreted as a test of additive method effects (according to Definition A2) against a more general pattern.

Not surprisingly, the CM model is also a particular case of the CFA models in which method loadings are equal to zero.

We finish this section on CFA models by referring to a recently developed variant of them, namely the true score model. The true score model for MTMM data is a reparametrization of the CFA model as a second-order factor analysis model sug- 
gested in Saris and Andrews (1991). Under this parametrization, each observed variable loads on a first-order factor representing the true score, that is, the observed score minus the random error term. The true score loads on one second-order trait factor and one second-order method factor. The true score model then makes a different decomposition of the variance of the observed variables. A true score model that is equivalent to the CFA3 model is used in Költringer (1995), Scherpenzeel (1995), and Scherpenzeel and Saris (1997). A true score model that is equivalent to the CFA4 model is used in Coenders et al. (1995).

\section{DP Model}

The DP model (Browne, 1984, 1985, 1989; Cudeck, 1988) has been developed drawing from the work of Swain (1975) with the specific aim of modeling multiplicative method effects. Unlike the previous models, the DP model is not a factor analysis model. It does not assume the variables to be related through a set of equations but only specifies a certain implied structure for the variances and covariances, ${ }^{1}$ which is displayed in Equation 24.

$\operatorname{var}\left(x_{i j}\right)=\left(1+e_{i j}\right) \mathrm{Z}^{2} i j$

$\operatorname{cov}\left(x_{i j} x_{i j^{\prime}}\right)=\pi_{j j^{\prime}} \rho_{i i^{\prime}} z_{i j} z_{i^{\prime \prime}} \quad$ if $i \neq i^{\prime}$ and $j \neq j^{\prime}$

$\operatorname{cov}\left(x_{i j} x_{i j}\right)=\rho_{i i^{\prime}} z_{i j} z_{i^{\prime} j} \quad$ if $i \neq i^{\prime}$

$\operatorname{cov}\left(x_{i j} x_{i j^{\prime}}\right)=\pi_{i j^{\prime}} z_{i j} z_{i j^{\prime}} \quad$ if $j \neq j^{\prime}$

where $x_{i j}$ is the measurement of trait $i$ with method $j$, expressed in deviations from the mean; $z_{i j}$ is a scaling constant for $x_{i j}$; $\rho_{i i}$ is the correlation between traits $i$ and $i$; $\pi_{i j}$ is a method effect indicator ${ }^{2}$ (in this model such effects are not given for every individual method, but for every combination of two of them); and $e_{i j}$ can be under-

\footnotetext{
${ }^{1}$ The DP model can also be viewed as a model for the observed measurements that specifies them as the product of two independent trait and method factors. However, the interpretation of such a multiplicative model for the measurements is problematic and involves rethinking the current measurement theory (Kumar \& Dillon, 1992; Marsh \& Grayson, 1995). In this section, the DP model will be considered only in terms of its implications for the covariances or correlations. The equivalence between the CUM2 and DP models derived in Coenders and Saris (1998) allows for a more appealing interpretation of the model.

${ }^{2}$ The model is sometimes interpreted in a symmetric fashion in which the $\pi_{i i^{\prime}}$ and $\rho_{i j}$ terms play exactly the same role and are interpreted as correlations (Browne, 1984, 1985; Cudeck, 1988). Traits and methods are then viewed as two facets of the MTMM design. Throughout this article it is assumed that researchers are mainly interested in corrected trait correlations and in measurement quality, which makes the interpretation of $\rho_{i i^{\prime}}$ as a trait correlation and of $\pi_{j j^{\prime}}$ as a method effect indicator more attractive.
} 
stood as a standardized random error variance. As shown in Equation $24, e_{i j}$ contributes to the variances and not to the covariances, and it therefore leads to an attenuation of correlations in the same way as a random error component does. A measurement quality indicator can be obtained as $1 /\left(1+e_{i j}\right)$ and an unstandardized random error variance as $e_{i j} z_{i j}^{2}$.

The DP model is scale invariant. Moreover, the parameters $e_{i j}, \rho_{i i^{\prime}}$, and $\pi_{j j^{\prime}}$ are scale free, which means that they are interpreted in the same way regardless of whether a covariance or a correlation matrix is analyzed (see Cudeck, 1989).

The $\rho_{i i^{\prime}}, \pi_{j j^{\prime}}$, and $\pi_{j j^{\prime}} \rho_{i i^{\prime}}$ terms in Equation 24 constitute the most interesting part of the model and are interpreted as correlations between the corresponding $x$ variables disattenuated for the effect of random measurement error. These disattenuated correlations take three possible forms:

1. A disattenuated heterotrait-monomethod correlation is equal to the $\rho_{i i^{\prime}}$ correlation between both traits.

2. A disattenuated heterotrait-heteromethod correlation is equal to the product of the $\rho_{i i^{\prime}}$ correlation between both traits and the $\pi_{j j^{\prime}}$ coefficient corresponding to the combination of both methods. The DP model takes method effects into account by means of these $\pi_{j j^{\prime}}$ coefficients because these coefficients are constrained to be equal to or lower than 1 in absolute value and therefore cause a reduction in the heterotrait-heteromethod correlations with respect to the heterotrait-monomethod correlations. Thus, the lower the $\pi_{j j}$ 's are, the larger the method effects are; if all the $\pi_{j j^{\prime}}$ coefficients were equal to 1 , no reduction in the correlations would take place, which could be interpreted as the absence of method effects. Actually, a DP model in which all $\pi_{j j}$ 's are constrained to be equal to 1 was shown to be equivalent to the CM model (Coenders \& Saris, 1998). Note that, in this model, method effects reduce heteromethod correlations, whereas in the CFA and CU models they increase monomethod correlations. Note also that this reduction in the heteromethod correlations is proportional to the trait correlations: It is clear that the difference between the heteromethod and monomethod correlations will be higher when the trait correlation is higher, thus leading to a multiplicative MTMM structure. If the $e_{i j}$ error variances are all equal, then the DP model implies a multiplicative correlation structure in the sense given by Campbell and O'Connell (1967).

3. A disattenuated monotrait-heteromethod correlation is equal to the corresponding $\pi_{j j^{\prime}}$ coefficient. This leads to another interpretation of the $\pi_{i j^{\prime}}$ coefficients, which is by no means in conflict with the former one: Once random measurement error has been taken into account, monotrait-heteromethod correlations should be equal to 1 except for the impact of method effects.

In the past, the model could not be estimated with standard software for structural equation modeling unless it was reparametrized as a second-order factor analysis model (Wothke \& Browne, 1990), which was very cumbersome and hard 
to interpret. As an alternative, Browne's program MUTMUM (Browne, 1985) could be used. Nowadays standard programs for structural equation models that include nonlinear constraints can be used. A parametrization of the DP model as a first-order factor analysis model with nonlinear constraints is shown in the appendix, where an input file for the LISREL8 program is also given.

The DP model is often presented as belonging to a completely different family of models from that of the CFA and CU. However, Coenders and Saris (1998) showed this not to be the case. These authors showed that the CM model is a particular case of the DP model in which there are no method effects. More interestingly, they also showed that the DP model is equivalent to the CUM2 model whenever $m$ $=3$. For a proof and the expression of the parameters we refer to Coenders and Saris.

What is most interesting about the relationships of the parameters of the CUM2 and DP models is that trait correlations are numerically the same for both models, in spite of the different way in which they take method effects into account.

The equivalence of the CUM2 and DP models for $m=3$ also implies that the DP model is nested into the $\mathrm{CU}$ model for these designs ${ }^{3}$ so that, in this particular case, a test of multiplicative method effects may be performed by comparing the fit of the CU and DP models. Note that the test of the CUM2 model against the CU model is valid for any value of $m$ and can equally be interpreted as a test for multiplicative method effects. The need for $m$ to be equal to 3 only applies if the researcher wishes to perform a test of the DP against the CU model. The CUM2 model can be used for any number of methods and can equally be interpreted as a model for multiplicative method effects, even if it is not strictly equivalent to the alternative DP model when $m \neq 3$.

As regards the generalization of the equivalence for other designs, if $m \neq 3$, then the number of free error covariances in the CUM2 model $(m)$ is not equal to the number of $\pi$ parameters in the DP model [ $m(m-1) / 2]$. In particular, if $m>3$, the CUM2 model is more parsimonious than the DP model and if $m=2$, it is the other way around. However, the results in Coenders and Saris (1998) hinted at the fact that the CUM2 model imposes the same kind of pattern on the covariances as the DP model. The authors showed that for $m>3$, the CUM2 model is equivalent to a constrained DP model. The fact that designs with three methods are quite common in practice must also be taken into account. Designs with less than three methods sometimes lead to models that are underidentified or at least to rather unstable estimates. Designs with more than three methods suffer from the high cost connected with profusely repeated measurement.

\footnotetext{
${ }^{3}$ The equivalence between the CU and CFA2 models, shown in Marsh (1989) for designs with $t=3$ also means that the DP model will be nested into the CFA2 and CFA1 models when $t=3$ and $m=3$. This explains the good performance of the CFA1 model in accounting for the observed correlations in MTMM matrices with a multiplicative structure (Bagozzi \& Yi, 1991; Kumar \& Dillon, 1992).
} 


\section{DISCUSSION}

In this article alternative definitions of additive and multiplicative method effects have been provided. These definitions are closely related to those given by Campbell and O'Connell in 1967 (even equivalent under some circumstances) and fit into the current modeling approaches as they can be implemented by means of constraints on the parameters of the $\mathrm{CU}$ model. The new definitions have been shown to have several advantages.

One advantage is that they in fact constitute a generalization of the definitions given by Campbell and O'Connell in 1967. As has been shown, both sets of definitions are identical when all measurement qualities are equal. When the opposite holds, our definitions are more easily interpretable than the ones suggested by Campbell and O'Connell.

A second advantage of the alternative definitions is that the fact that they can be implemented by means of constraints makes them highly operative: They allow us to test additive and multiplicative method effects against more general patterns by simply testing the constraints. The hierarchy of nested MTMM models presented in Widaman (1985) was mainly suggested as a way of testing the existence of method effects. The hierarchy presented in this article is suggested as a way of testing the pattern of method effects.

The outcome of the tests can often have interesting substantive implications. Bagozzi and Yi (1991), in line with Campbell and O'Connell (1967), suggested that multiplicative structures are quite common when methods consist of raters. Raters may have their own theories regarding the co-occurrence of certain phenomena that are related to one another. It is therefore expected that the correlation among measurements of related traits will be inflated by more than the correlation among measurements of relatively independent traits. Coenders (1996, chap. 5) suggests that ordinal measurement also leads to multiplicative method effects because the categorization errors of closely related variables can be correlated. Andrews (1984) and Kumar and Dillon (1992) argued that, when methods consist of category labels or scale lengths in questionnaires, an additive structure is more reasonable. In such cases, method effects are likely to arise from individual differences in the use of the response scale, which can be expected to be reasonably constant across traits. Researchers seeking to make such substantive statements on the nature of method effects can benefit from the tests described in this article. Researchers comparing the performance of the existing CFA, DP, and CU models (e.g., Bagozzi, 1993; Bagozzi \& Yi, 1991) can also use the tests described in this article, at least for some very common designs.

A third advantage of the alternative definitions is that they are also closely related to other models that are normally used to fit additive and multiplicative structures. Namely, CU models with constraints according to Definitions A1 or A2 are equivalent to additive versions of the CFA model, and the CU model with con- 
straints according to Definition M2 is equivalent to the DP model (for designs with three methods). The DP and CUM2 models, although formally very different, behave in a very similar way, performing the same corrections on trait correlations and relying on similar assumptions. The CFA3, CFA4, and DP models are nested into the more general unrestricted CU model, which shows the CU model to be a very general framework for MTMM analysis. An overview of all models is given in Table 4, and the relationships among them are indicated in Figure 2.

A fourth advantage of our new definitions is that the derived relationship between the DP, CM, and CUM2 models allows us to better interpret the meaning of the parameters and assumptions of the DP model and solve some of the frequent misunderstandings that appear in the literature on this subject.

The fact that the $\pi_{j j}$, parameters have often been called method correlations is the source of one of such misunderstanding. In fact, these parameters have sometimes been interpreted in the same way as method factor correlations are interpreted in the framework of the CFA1 model, that is, as sources of heteromethod error covariances. Quite differently, high values of $\pi_{j j^{\prime}}$ (i.e., close to 1 ) do not show that heteromethod error covariances are high but that method effects are low-in other words, that the differences between monomethod and heteromethod correlations are low (DP interpretation) or that monomethod error covariances are low (CUM2 interpretation). In the extreme, if all $\pi_{j j^{\prime}}$ terms are equal to 1 , then there are no method effects at all and, accordingly, the DP model becomes equivalent to the CM model.

As a result of the aforementioned misunderstanding, some literature (e.g., Bagozzi, 1993) claimed that, unlike the CFA2, CFA3, CFA4, and CU models, the DP model can account for heteromethod error covariances by means of the $\pi_{i j^{\prime}}$ parameters. The fact that the DP model is nested into the $\mathrm{CU}$ model proves that the DP model cannot be less restrictive than the $\mathrm{CU}$ model in this respect, at least when $m=3$.

The claim made by Campbell and O'Connell (1982) that, under some circumstances, monomethod correlations should be more realistic than heteromethod correlations, together with the fact that the DP model trait correlations are related to monomethod correlations, could lead to another misunderstanding: It could be suggested that the trait correlation estimates obtained from the DP model can be more appropriate than those obtained from the CU model. The fact that the $\rho_{i i^{\prime}}$ parameters of the DP model equal the $\phi_{i i^{\prime}}$ parameters of the CUM2 model implies that they both can be interpreted as trait factor correlations that are corrected for both random errors and method effects in exactly the same way.

A fifth advantage of the definitions is that they allow researchers willing to model multiplicative method effects to use the CUM2 model instead of the DP model. The CUM2 model offers the advantage of being more comparable to standard models. Note that the CUM2 model may be used also if $m>3$. In this case, it is not equivalent to the DP model, but it continues to model multiplicative method 
effects in the sense given by Campbell and O'Connell (1967). As far as we know, the CU family of models has never been used to deal with multiplicative MTMM structures, probably because the additive formulation of the models did not suggest this possibility. Many a researcher who finds the DP model hard to interpret can benefit from adopting the CU family of models instead.

To cope with scale dependencies in MTMM analyses, two sets of definitions have been provided in this article. Definitions A2 and M2 should in principle be preferred because they lead to scale invariant models. However, provided that the covariance matrix is analyzed, the researcher may still choose Definitions A1 and M1 if the units of measurement remain constant within a method and the trait loadings are of about the same magnitude within a method, which is a quite common situation. Definition A1 is particularly appealing because it involves only linear constraints.

Definitions A1 and A2 imply that all error covariances must be positive, and Definitions M1 and M2 imply that all error covariances must be of the same sign as their respective trait correlations. This must be taken into account by practitioners when fitting these models and merely reflects the typical behavior of additive and multiplicative method effects. The CFA3 model and Campbell and O'Connell's definition of multiplicative method effects also have this behavior.

The article has shown that, with or without additional constraints, the $\mathrm{CU}$ model can be used for additive, multiplicative, and even more general structures and constitutes a generalization of many other models. This suggests that this model can be used on a very general basis for carrying out MTMM analyses.

A drawback of the $\mathrm{CU}$ model is that it assumes that heteromethod error covariances are zero. In some circumstances, some of the methods of measurement are so similar that this assumption cannot be expected to hold (de Wit, 1994). The literature suggests that such phenomena are quite frequent and high heteromethod error covariances are to be expected when all methods consist in self-rating (e.g., Andrews \& Withey, 1976, chap. 6; Bagozzi, 1993). In any case, this assumption has rarely been successfully relaxed in applied research: The DP, CFA2, CFA3, and CFA4 models also make this assumption, which is only relaxed by the CFA1 model, which is often subject convergence, inadmissibility, and underidentification problems (Andrews, 1984; Bagozzi \& Yi, 1991; Brannick \& Spector, 1990; Kenny \& Kashy, 1992; Marsh \& Bailey, 1991; Rindskopf, 1984; Saris, 1990b). In addition, some literature suggests that, even when heteromethod error covariances are present, the bias of the estimates when fitting models that assume zero heteromethod error covariances is fairly minor (Saris, 1990a; Scherpenzeel, 1995), at least if method effects are not too high. Marsh (1989) and Marsh and Bailey (1991) went further to show that, even in the cases in which the $\mathrm{CU}$ model is misspecified due to heteromethod error covariances, the CU estimates are closer to the population parameter values than the estimates of the correctly specified but highly unstable CFA1 model. The comparatively better 
performance of the $\mathrm{CU}$ model occurs because the lower sampling variability of the CU estimates outweighs the bias arising from the violation of the model's assumptions. Therefore, in our opinion and from a practical point of view, the restrictive assumptions of the $\mathrm{CU}$ model are not so serious and are more than compensated for by the model's lack of practical problems: Marsh (1989) and Marsh and Bailey (1991) reported that the CU model rarely leads to problems of empirical underidentification, failure to converge, or inadmissible estimates.

\section{ACKNOWLEDGMENTS}

Germà Coenders is now on the Faculty of Economics, University of Girona, Spain.

The work of Germà Coenders was partly supported by CIRIT Grant 1995BEAI200026 from the Catalan Autonomous Government.

The authors wish to thank Albert Satorra and Joan Manuel Batista-Foguet for their useful comments, which greatly improved the article, and Patricia Mathews for correcting the English.

An earlier version of this article was presented at the 20th Biennial Conference of the Society for Multivariate Analysis in the Behavioral Sciences, Barcelona, July 8-10, 1996.

\section{REFERENCES}

Althauser, R. P., Heberlein, T. A., \& Scott, R. A. (1971). A causal assessment of validity: The augmented multitrait-multimethod matrix. In H. M. Blalock, Jr. (Ed.), Causal models in the social sciences (pp. 151-169). Chicago: Aldine.

Alwin, D. (1974). An analytic comparison of four approaches to the interpretation of relationships in the multitrait-multimethod matrix. In H. L. Costner (Ed.), Sociological methodology 1973-1974 (pp. 79-105). San Francisco: Jossey-Bass.

Andrews, F. M. (1984). Construct validity and error components of survey measures. A structural modeling approach. Public Opinion Quarterly, 48, 409-442.

Andrews, F. M., \& Withey, S. B. (1976). Social indicators of well-being. Americans' perceptions of life quality. New York: Plenum.

Bagozzi, R. P. (1993). Assessing construct validity in personality research. Applications to measures of self-esteem. Journal of Research in Personality, 27, 49-87.

Bagozzi, R. P., \& Yi, Y. (1991). Multitrait-multimethod matrices in consumer research. Journal of Consumer Research, 17, 426-439.

Batista-Foguet, J. M., Coenders, G., \& Sureda, J. (1996). Satisfaction in Catalonia, Spain. In W. E. Saris, R. Veenhoven, A. C. Scherpenzeel, \& B. Bunting (Eds.), A comparative study of satisfaction with life in Europe (pp. 155-174). Budapest, Hungary: Eötvös University Press.

Bollen, K. A. (1989). Structural equations with latent variables. New York: Wiley.

Brannick, M. T., \& Spector, P. E. (1990). Estimation problems in the block-diagonal model of the multitrait-multimethod matrix. Applied Psychological Measurement, 14, 325-339.

Browne, M. W. (1984). The decomposition of multitrait-multimethod matrices. British Journal of Mathematical and Statistical Psychology, 37, 1-21. 
Browne, M. W. (1985). MUTMUM, decomposition of multitrait-multimethod matrices. Pretoria, South Africa: University of South Africa, Department of Statistics.

Browne, M. W. (1989). Relationships between an additive model and a multiplicative model for multitrait-multimethod matrices. In R. Coppi \& S. Bolasco (Eds.), Multiway data analysis (pp. 507-520). Amsterdam: North-Holland.

Browne, M. W., \& Cudeck, R (1993). Alternative ways of assessing model fit. In K. A. Bollen \& J. S. Long (Eds.), Testing structural equation models (pp. 136-162). Newbury Park, CA: Sage.

Campbell, D. T., \& Fiske, D. W. (1959). Convergent and discriminant validation by the multitrait-multimethod matrices. Psychological Bulletin, 56, 81-105.

Campbell, D. T., \& O'Connell, E. J. (1967). Method factors in multitrait-multimethod matrices: Multiplicative rather than additive? Multivariate Behavioral Research, 2, 409-426.

Campbell, D. T., \& O'Connell, E. J. (1982). Methods as diluting trait relationships rather than adding irrelevant systematic variance. In D. Brinberg \& L. Kidder (Eds.), Forms of validity in research (pp. 93-111). San Francisco: Jossey-Bass.

Coenders, G. (1996). Structural equation modeling of ordinally measured survey data. Doctoral dissertation, ESADE, University Ramon Llull, Barcelona, Spain.

Coenders, G., Batista-Foguet, J. M., \& Satorra, A. (1995). Scale dependence of the true score MTMM model. In W. E. Saris \& Á. Münnich (Eds.), The multitrait-multimethod approach to evaluate measurement instruments (pp. 71-87). Budapest, Hungary: Eötvös University Press.

Coenders, G., \& Saris, W. E. (1998). Relationship between a restricted correlated uniqueness model and a direct product model for multitrait-multimethod data. In A. Ferligoj (Ed.), Advances in methodology, data analysis and statistics: Metodološki zvezki 14 (pp. 151-172). Ljubljana, Slovenia: FDV.

Cudeck, R. (1988). Multiplicative models and MTMM matrices. Journal of Educational Statistics, 13, 131-147.

Cudeck, R. (1989). Analysis of correlation matrices using covariance structure models. Psychological Bulletin, 105, 317- 327.

de Wit, H. (1994). Cijfers en hun achterliggende realiteit. De MTMM-kwaliteitsparameters op hun kwaliteit onderzocht [Numbers and their underlying reality. The MTMM quality parameters for measurement quality research]. Doctoral dissertation, Catholic University of Leuven, Belgium.

Dudgeon, P. (1994). A reparametrization of the restricted factor analysis model for multitrait-multimethod matrices. British Journal of Mathematical and Statistical Psychology, 47, 283-308.

Jöreskog, K. G. (1969). A general approach to confirmatory maximum likelihood factor analysis. Psychometrika, 34, 183-202.

Jöreskog, K. G. (1971). Statistical analysis of congeneric tests. Psychometrika, 36, 109-133.

Jöreskog, K. G., \& Sörbom, D. (1989). LISREL7, a guide to the program and applications. Chicago: SPSS.

Jöreskog, K. G., \& Sörbom, D. (1993). Newfeatures in LISREL8. Chicago: Scientific Software International.

Kenny, D. A. (1976). An empirical application of confirmatory factor analysis to the multitrait-multimethod matrix. Journal of Experimental Social Psychology, 12, 247-252.

Kenny, D. A., \& Kashy, D. A. (1992). Analysis of the multitrait-multimethod matrix by confirmatory factor analysis. Psychological Bulletin, 112, 165-172.

Költringer, R. (1995). Measurement quality in Austrian personal interview surveys. In W. E. Saris \& Á. Münnich (Eds.), The multitrait-multimethod approach to evaluate measurement instruments (pp. 207-224). Budapest, Hungary: Eötvös University Press.

Kumar, A., \& Dillon, W. R. (1992). An integrative look at the use of additive and multiplicative covariance structure models in the analysis of MTMM data. Journal of Marketing Research, 29, 51-64.

Luijben, T. (1989). Statistical guidance for model modification in covariance structure analysis. Amsterdam: Sociometric Research Foundation. 
Marsh, H. W. (1989). Confirmatory factor analysis of multitrait-multimethod data: Many problems and few solutions. Applied Psychological Measurement, 13, 335-361.

Marsh, H. W., \& Bailey, M. (1991). Confirmatory factor analyses of multitrait-multimethod data: Comparison of the behavior of alternative models. Applied Psychological Measurement, 15, 47-70.

Marsh, H. W., \& Grayson. D. (1995). Latent variable models of multitrait-multimethod data. In R. H. Hoyle (Ed.), Structural equation modeling. Concepts, issues and applications (pp. 177-198). Thousand Oaks, Ca: Sage.

Rindskopf, D. (1984). Structural equation models: Empirical identification, Heywood cases and related problems. Sociological Methods and Research, 13, 109-119.

Saris, W. E. (1990a). Models for evaluation of measurement instruments. In W. E. Saris \& A. van Meurs (Eds.), Evaluation of measurement instruments by meta-analysis of multitrait multimethod matrices (pp. 52-80). Amsterdam: North-Holland.

Saris, W. E. (1990b). The choice of a model for evaluation of measurement instruments. In W. E. Saris \& A. van Meurs (Eds.), Evaluation of measurement instruments by meta-analysis of multitrait multimethod matrices (pp. 118-129). Amsterdam: North-Holland.

Saris, W. E., \& Andrews, F. M. (1991). Evaluation of measurement instruments using a structural modeling approach. In P. P. Biemer, R. M. Groves, L. E. Lyberg, N. Mathiowetz, \& S. Sudman (Eds.), Measurement errors in surveys (pp. 575-599). New York: Wiley.

Saris, W. E., \& Satorra, A. (1988). Characteristics of structural equation models which affect the power of the likelihood ratio test. In W. E. Saris \& I. N. Galhofer (Eds.), Sociometric research: Vol. 2. Data analysis (pp. 220-236). New York: Macmillan.

Saris, W. E., \& Satorra, A. (1993). Power evaluations in structural equation models. In K. A. Bollen \& J. S. Long (Eds.), Testing structural equation models (pp. 181-204). Newbury Park, CA: Sage.

Saris, W. E., Satorra, A., \& Sörbom, D. (1987). The detection and correction of specification errors in structural equation models. In C. C. Clogg (Ed.), Sociological methodology 1987 (pp. 105-129). Washington, DC: American Sociological Association.

Saris, W. E., \& Stronkhorst, L. H. (1984). Causal modelling in nonexperimental research: An introduction to the LISREL approach. Amsterdam: Sociometric Research Foundation.

Satorra, A. (1990). Robustness issues in structural equation modeling: A review of recent developments. Quality and Quantity, 24, 367-386.

Satorra, A., \& Saris, W. E. (1985). The power of the likelihood ratio test in covariance structure analysis. Psychometrika, 50, 83-90.

Scherpenzeel, A. C. (1995). A question of quality. Evaluating survey questions by multitrait-multimethod studies. Doctoral dissertation, University of Amsterdam. Leidschendam, The Netherlands.

Scherpenzeel, A. C., \& Saris, W. E. (1997). The validity and reliability of survey questions. A meta analysis of MTMM studies. Sociological Methods and Research, 25, 341-383.

Schmitt, N., \& Stults, D. N. (1986). Methodology review. Analysis of multitrait-multimethod matrices. Applied Psychological Measurement, 10, 1-22.

Swain, A. J. (1975). Analysis of parametric structures for variance matrices. Doctoral dissertation, University of Adelaide.

Tanaka, J. S. (1993). Multifaceted conceptions of fit in structural equation models. In K. A. Bollen \& J. S. Long (Eds.), Testing structural equation models (pp. 10-39). Newbury Park, CA: Sage.

Werts, C. E., \& Linn, R. L. (1970). Path analysis. Psychological examples. Psychological Bulletin, 74, 193-212.

Widaman, K. F. (1985). Hierarchically nested covariance structure models for multitrait-multimethod data. Applied Psychological Measurement, 9, 1-26.

Wothke, W. (1984). The estimation of trait and method components in multitrait-multimethodmeasurement. Doctoral dissertation, University of Chicago.

Wothke, W., \& Browne, M. W. (1990). The direct product model for the MTMM matrix parametrized as a second order factor analysis model. Psychometrika, 55, 255-262. 


\section{APPENDIX}

\section{Parametrizations of Multiplicative MTMM Models}

The CUM2 Model with Nonlinear Constraints in the Error Covariance Matrix

This parametrization involves the usual specification of a CU model with the appropriate nonlinear constraints in the nonzero error covariances shown in Equation 16. In Figure A1, a LISREL 8 input file for $t=3$ and $m=3$ is provided. Note that, in LISREL8 input files, subindexes refer to the row and column of a matrix of parameters and not to the trait and method.

The DP Model as a Factor Analysis Model with Constrained Factor Covariance Matrix

In this parametrization there are $m t$ factors and each of the $m t x_{i j}$ observed variables loads only on one $\xi_{i j}$ factor and has a zero error variance:

$$
x_{i j}=\lambda_{i j} \xi_{i j}
$$

The factor covariance matrix contains the terms $1+e_{i j}$ in the diagonal and the disattenuated correlations outside the diagonal. The values outside the diagonal

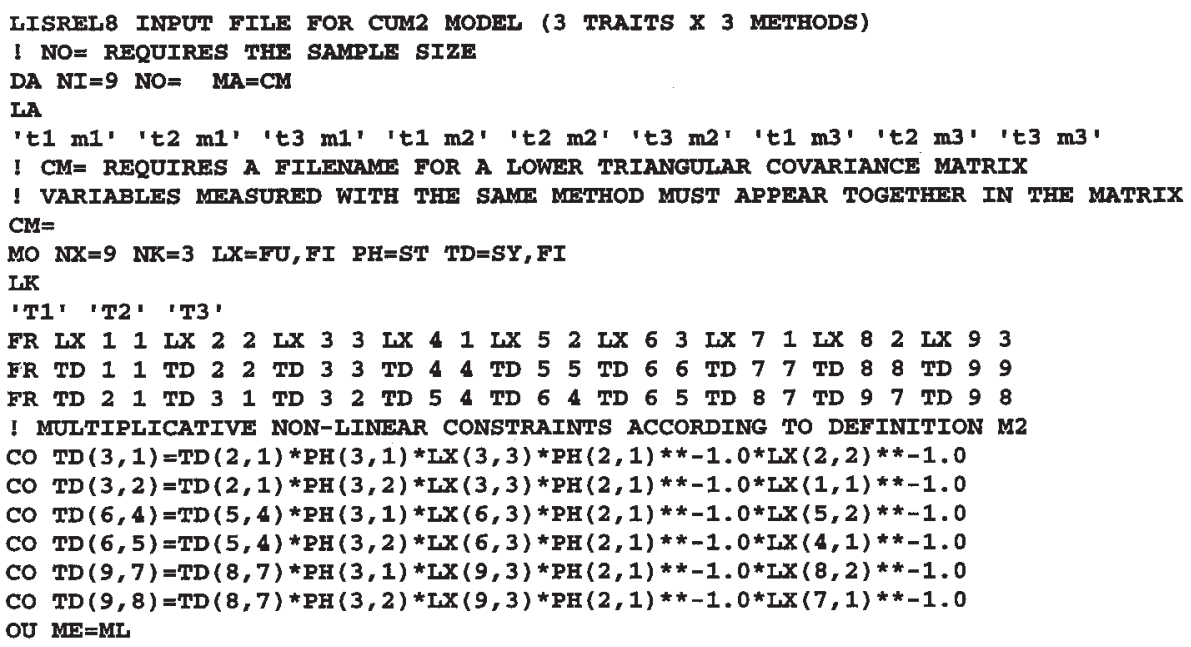

FIGURE A1 LISREL8 input file for the CUM2 model for three traits and three methods. Maximum likelihood estimation. 
must then be constrained to appropriate products among a set of free $\pi_{j j}$, and $\rho_{i i}$, parameters. The $\lambda_{i j}$ factor loadings play the role of the $z_{i j}$ terms.

Following are the implied variances and covariances of this parametrization and of the DP model:

$$
\operatorname{var}\left(x_{i j}\right)=\operatorname{var}\left(\xi_{i j}\right) \lambda^{2}{ }_{i j}=\left(1+e_{i j}\right) z_{i j}^{2}
$$

IISREL8 INPUT FILE FOR DP MODEL ( 3 TRAITS $x$ METHODS)

1 PARAMETRIZED AS A FA MODEL WITH 9 FACTORS WITH NON-LINEAR CONSTRAINTS

I THE OFF-DIAGONAL PHI MATRIX IS THE 9X9 DISATTENUATED CORRTIATION MATRIX

I THE DIAGONAT OF PHI CONTAINS $1+e(i j)$ AND IS UNCONSTRAINED

I IX CONTAINS THE SCALING FACTORS $z$ (ij)

! NO= REQUIRES THE SAMPLE SIZE

DA NI $=9$ NOF $\quad \mathrm{MA}=\mathrm{CM}$

I.A

't1 m1' 't2 ml' 't3 m1' 't1 m2' 't2 m2' 't3 m2' 't1 m3' 't2 m3' 't3 m3'

! $C M=$ REQUIRES A FIIENAME FOR A LOWER TRIANGULAR COVARIANCE MATRIX

! VARIABLES MEASURED WITH THE SAME METHOD MUST APPEAR TOGETHER IN THE MATRIX

$\mathrm{CM}=$

MO NX=9 NK=9 TD=ZE IX=DI, FR PH=SY, FR

IK

'T1M1' 'T2M1' 'T3M1' 'T1M2' 'T2M2' 'T3M2' 'T1M3' 'T2M3' 'T3M3'

$\mid$ RESTRICTIONS TO THE STRUCTURE OF THE DISATTENUATED CORRELATION MATRIX

I DISATTENUATED HETEROTRAIT-MONOMETHOD CORREL, ThO(ii') EQUAL FOR ALL MITHODS

EQ PH 21 PH 5 \& PH 87

FQ PH $3 \quad 1$ PH 64 PH 97

EQ PH 32 PH 65 PH 98

I DISATPENUATED MONOTRAIT-HETEROMETHOD CORREL. pi (jj') FQUAL FOR ALL TRAITS

EQ PH $4 \begin{array}{lllllll} & 1 & \text { PH } & 2 & \text { PHE } & 6 & 3\end{array}$

$\begin{array}{llllllllll}E Q & \text { PH } & 7 & 1 & \text { PH } & 8 & 2 & \text { PH } & 9 & 3\end{array}$

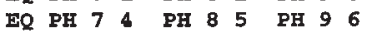

I 18 DISATTENUATED HETEROTRAIT-HETFROMETHOD CORRELATIONS

! CONSTRAINED TO THE PRODUCT OF ONE rho(ii') THEM AND ONE pi(jj') TERM

CO PH $(5,1)=\mathrm{PH}(2,1) * \mathrm{PH}(4,1)$

CO PH $(6,1)=\mathrm{PH}(3,1) * \mathrm{PH}(4,1)$

CO PH $(6,2)=\mathrm{PH}(3,2) * \mathrm{PH}(4,1)$

CO PH $(4,2)=\mathrm{PH}(2,1) * \mathrm{PH}(4,1)$

CO $\mathrm{PH}(4,3)=\mathrm{PH}(3,1) * \mathrm{PH}(4,1)$

CO $\mathrm{PH}(5,3)=\mathrm{PH}(3,2) * \mathrm{PH}(4,1)$

CO PH $(8,1)=$ PH $(2,1) * \mathrm{PH}(7,1)$

CO PH $(9,1)=\operatorname{PH}(3,1) * \operatorname{PH}(7,1)$

CO $\mathrm{PH}(9,2)=\mathrm{PH}(3,2) * \mathrm{PH}(7,1)$

Co $\mathrm{PH}(7,2)=\mathrm{PH}(2,1) * \mathrm{PH}(7,1)$

CO PH $(7,3)=$ PH $(3,1) * P E(7,1)$

CO PH $(8,3)=\operatorname{PH}(3,2) * \mathrm{PH}(7,1)$

CO PH $(8,4)=\operatorname{PH}(2,1) * \mathrm{PH}(7,4)$

Co PH $(9,4)=\mathrm{PH}(3,1) * \mathrm{PH}(7,4)$

CO PH $(9,5)=\mathrm{PH}(3,2) * \mathrm{PH}(7,4)$

CO $\mathrm{PH}(7,5)=\mathrm{PH}(2,1) * \mathrm{PH}(7,4)$

CO PH $(7,6)=\mathrm{PH}(3,1)$ * $\mathrm{PH}(7,4)$

CO $\mathrm{PH}(8,6)=\mathrm{PH}(3,2) * \mathrm{PH}(7,4)$

! STARTING VALUES FOR THE ESTIMATION

! WE RECOMMIND GIVING THE IX PARAMETERS VALUES CLOSE TO THE STANDARD DEVIATIONS

ST $\quad .5$ PH 21 PH 31 PH 32

ST .9 PH $4 \begin{array}{lllllll} & 1 & \text { PH } & 1 & \text { PH } & 4 & 4\end{array}$

$\begin{array}{llllllllllllllllllllllllllllll}\text { ST } & 9 & L X & 1 & 1 & L X & 2 & 2 & L X & 3 & 3 & L X & 4 & 4 & L X & 5 & 5 & L X & 6 & 6 & L X & 7 & 7 & L X & 8 & 8 & L X & 9 & 9\end{array}$

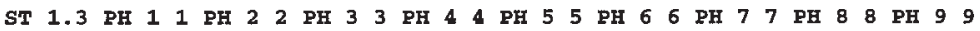

OU NS $M E=M L$

FIGURE A2 LISREL8 input file for the DP model for three traits and three methods. Maximum likelihood estimation. 


$$
\begin{gathered}
\operatorname{cov}\left(x_{i j} x_{i^{\prime} j^{\prime}}\right)=\operatorname{cov}\left(\xi_{i j} \xi_{i^{\prime} j^{\prime}}\right) \lambda_{i j} \lambda_{i^{\prime} j^{\prime}}=\pi_{j j^{\prime}} \rho_{i i^{\prime}} z_{i j} z_{i^{\prime} j^{\prime}} \\
\operatorname{cov}\left(x_{i j} x_{i^{\prime} j}\right)=\operatorname{cov}\left(\xi_{i j} \xi_{i^{\prime} j}\right) \lambda_{i j} \lambda_{i^{\prime} j}=\rho_{i i^{\prime}} z_{i j} z_{i^{\prime} j} \\
\operatorname{cov}\left(x_{i j} x_{i j^{\prime}}\right)=\operatorname{cov}\left(\xi_{i j} \xi_{i j^{\prime}}\right) \lambda_{i j} \lambda_{i j^{\prime}}=\pi_{j j^{\prime}} z_{i j} z_{i j^{\prime}}
\end{gathered}
$$

In Figure A2, a LISREL8 input file for $t=3$ and $m=3$ is provided. 